\title{
Diabetes and Migration
}

\author{
Authors \\ Sebahat Şat ${ }^{1,2}$, Kadriye Aydınkoç-Tuzcu2, 4, 6, Faize Berger², Alain Barakat², 3, Karin Schindler5, 6, Peter Fasching4, 6
}

Affiliations

1 MVZ DaVita Rhine-Ruhr, Düsseldorf, Germany

2 DDG Working Group on Diabetes and Migrants, Germany

3 Diabetes Center Duisburg Center DZDM, Germany

4 Wilhelminenspital of the City of Vienna, 5th Medical Department of Endocrinology, Rheumatology and Acute Geriatrics, Vienna, Austria

5 Medical University of Vienna, University Clinic for Internal Medicine III, Clinical Department of Endocrinology and Metabolism, Vienna, Austria

6 ÖDG Working Group on Migration and Diabetes, Germany

published online $\quad 14.04 .2021$

\section{Bibliography}

Exp Clin Endocrinol Diabetes 2021; 129: S106-S118

DOI $10.1055 / a-1284-6778$

ISSN 0947-7349

(C) 2021. Thieme. All rights reserved.

Georg Thieme Verlag KG, Rüdigerstraße 14,

70469 Stuttgart, Germany

German Diabetes Association: Clinical Practice Guidelines This is a translation of the DDG clinical practice guideline published in Diabetologie 2020; 15 (Suppl 1): S232-S248. DOI 10.1055/a-1194-2962

\section{Correspondence}

Corresponding authors DDG

Sebahat Şat

MVZ DaVita Rhine-Ruhr

Bismarckstr. 101

40210 Düsseldorf

Germany

Sebahat.Sat@davita.de

Faize Berger

Chairperson

Working Group on Diabetes and Migration/Vorsitzende der AG Diabetes und Migranten der DDG

c/o Deutsche Diabetes Gesellschaft

Albrechtstraße 9

10117 Berlin

Germany

fb@faizeberger.com

Corresponding authors ÖDG

Kadriye Aydınkoç-Tuzcu

Klinik Ottakring

5. Medizinische Abteilung mit Endokrinologie

Rheumatologie und Akutgeriatrie

Montlearstrasse 37

1160 Vienna

Austria

kadriyeaydinkoc@yahoo.de
The practical recommendation "Diabetes and Migration" of the German Diabetes Society e. V. (DDG) was prepared for the first time and in cooperation with the Austrian Diabetes Society (ÖDG). The practice recommendation is intended to supplement the existing guidelines on diabetes mellitus and provides practical recommendations for the diagnosis, therapy and care of people with diabetes mellitus who come from different linguistic and cultural backgrounds.

\section{Definition (Migration Background and Generation)}

The population with a migration background includes people with their own migration experience and all those who have at least one parent or grandparent to whom this applies [1]. Different definitions or changes in what is understood by a migrant background make it difficult to have a uniform and consistent view [2].
In the context of therapy, in addition to the pure migration background, the generational affiliation or the place of socialization plays an important role:

- First generation: socialization took place in the country of origin and immigration took place in adulthood.

- Second generation: children of the first generation born here or whose family moved here when they were under 18 years old. Their socialization has taken place, at least in part, in Germany.

- Third generation: first-generation grandchildren and second-generation children. Their socialization has taken place entirely in Germany.

\section{Data Situation}

In many official statistics and routine data, nationality is still considered the predominant distinguishing feature, which is used to 
represent only a selective part of the migrant population, however socio-demographic information is missing. People with a migration background often differ in their health situation from people without a migration background simply because of their younger average age or their poorer social situation. To make meaningful comparisons, the influence of these factors must be taken into account [2].

Despite an incomplete data situation in Germany, studies from comparable countries make it possible to obtain an approximate picture of the situation in Germany. Today, it can be assumed that more than 600000 people with type 2 diabetes with a migration background are living in Germany. This number will continue to grow in the coming years for two main reasons. Firstly, the first generation of migrants is increasingly reaching retirement age and secondly, many of the refugees coming to Germany come from countries with a high risk of developing type 2 diabetes. This effect is increased when they migrate to industrialized countries [3].

\section{Demographics for Germany}

In 2019, about 21.2 million (26\%) people in Germany had a migration background. This represented an increase of $2.1 \%$ over the previous year. The most important countries of origin continue to be Turkey (13\%), followed by Poland (11\%) and the Russian Federation (7\%) [4].

Currently, 2.3 million people from the Near and Middle East live in Germany. In addition, there is an increase in the number of people of African origin, although they only account for about $4 \%$ of the population with a migration background $[5,6]$. The resulting change in the population structure, combined with greater cultural diversity, poses major challenges for the health care system in Germany.

Since 2017, the micro census has been asking these persons about the main reason for immigration; the most important motive was family reasons.

Of the 24.0 million multi-person households in Germany, 2.5 million have predominantly used a foreign language. The most frequently used languages have been Turkish (17\%), Russian (15\%), Polish ( $8 \%$ ) and Arabic (7\%). The majority of multi-person households in which all household members had foreign roots communicated predominantly in a foreign language ( $55 \%$ ). If, on the other hand, only some of the household members had foreign roots, the proportion dropped to $7 \%$ [5].

\section{Prevalence for Germany}

The risk of developing type 2 diabetes varies greatly among migrant populations. People from South and Central America, North and Sub-Saharan Africa, the Middle East and South Asia have very high prevalence rates [7]. Numerous European and American studies confirm that the prevalence, incidence and mortality of type 2 diabetes are usually higher among migrants than among the native population [8]. In addition, migrants are on average 5-10 years earlier and more likely to develop type 2 diabetes compared to the population in their home countries and to the population in their adopted country $[3,9]$.
A recent meta-analysis of the prevalence of ethnic minorities in Europe shows that migrants from South and Central America are $30 \%$ more at risk than the native population.

In contrast, the risk is almost three times higher for migrants from the Middle East and North Africa and almost four times higher for migrants from South Asia [10-12].

Women of Turkish origin in Sweden have a 3-times higher risk of diabetes compared to Swedish women, whereas there is hardly any difference for men. This is the same for the hospitalization risk due to type 2 diabetes, although this effect is reduced in the second generation [13]. A study conducted in 7 European countries for 30 immigrant groups shows that the diabetes mortality rate for men and women is $90 \%$ and $120 \%$ higher respectively compared to the native population [14]. In addition, people with type 2 diabetes from Asia, the Middle East and sub-Saharan Africa have a particularly high risk of microvascular complications: diabetic retinopathy, nephropathy and peripheral neuropathy [15].

Increased disease rates are also seen in gestational diabetes. In Germany, for example, women of Turkish origin have a 33 \% higher incidence rate of gestational diabetes compared to native Germans [16].

\section{Demography for Austria}

According to Statistics Austria, 8.9 million people live in Austria, of which a total of 2.0 million have a migrant background. This is 51900 more than in 2017, which represents a share of about $23.7 \%$ [17]. The group of first-generation immigrants comprises about 1528000 persons, while second-generation immigrants number about 542 000. The largest group comes from Germany with 200 000 persons, followed by 123500 Romanians. In the course of 2019, these have overtaken Serbian (122 100) and Turkish citizens (117600). Bosnia and Herzegovina occupy fifth place (96 600). The citizens of Hungary, Croatia, Poland, Syria and Afghanistan are in sixth to tenth place. In addition, migrants from Slovakia, the Russian Federation, Italy, Bulgaria, Kosovo and Macedonia are also strongly represented in Austria.

\section{Prevalence for Austria}

In Austria, the group of people suffering from diabetes mellitus is currently estimated at 515000 to 809000 people (approx. 7 to $11 \%)$. The total includes 368000 to 515000 medically-diagnosed diabetes cases (approx. 5 to $7 \%$ ) and an estimated 147000 to 294000 diabetics (approx. 2 to $4 \%$ ). In the group of 0 to 14-yearolds, a proportion of people with diabetes of about $0.1 \%$ is assumed for Austria (approx. 1600 children) [18]. According to the IDF (International Diabetes Federation), the prevalence of diabetes in Austria is $9.3 \%$. Among migrants, the prevalence is about $10-12 \%$, although a high number of undiagnosed patients is assumed [19]. In Vienna, a patient survey confirmed a diabetes prevalence of $10 \%$ among Turkish migrants. Every third respondent had an increased risk of developing diabetes within the next five years [20]. Compared to native Austrians, migrants are 1.39 times more likely to develop diabetes among men and 3.4 times more likely among women [21]. 


\section{Particularities in the Diagnosis and Therapy of Migrants with Diabetes}

Due to their different cultural and individual backgrounds (level of education, reason and duration of migration, etc.), migrants often have a different understanding of health, healthcare, illness - especially chronic illness - than the native population. Knowledge of the connections between lifestyle and disease and of factors influencing the course of the disease often also differs from that of the native population [22]. In addition, lifestyle and nutritional habits in particular change as a result of the new social and economic conditions. Furthermore, external risk factors - structural deprivation - play an important role: these include location-specific (e.g. high unemployment), psychosocial factors (e.g. insecure employment) and environmental (e.g. noise, air pollution, climate change, etc.) factors [23].

The cultural background and in some cases a lack of language skills, illiteracy, low socio-economic status and difficulties in the process of cultural adaptation (acculturation) can therefore hinder access to medical preventative care and treatment. This is also reflected in the low percentage of migrants who seek screening [24].

\section{Treatment of People with Migration Background and Diabetes in Practice}

\section{General conditions}

The goals in the treatment of people with a migration background and diabetes are to enable an optimal transfer of knowledge and to strengthen the patients' personal responsibility. Appropriate information events are useful in order to increase knowledge about diabetes mellitus, the secondary and concomitant diseases as well as the relationship between the disease, diet and lifestyle. Starting points for this can be found in the respective communities with the involvement of all interest groups involved (such as cultural associations, religious communities, health insurance companies, medical societies, media).

In the inpatient and outpatient sector - especially in practices specializing in diabetology - a culturally sensitive approach with appropriately trained personnel (with special knowledge and understanding of the cultural influence on treatment) is an important prerequisite for successful therapy.

If a language barrier exists, training and treatment adapted to the mother tongue, educational level and lifestyle can be provided if possible. Intercultural content should be incorporated into the education, training and continuing education of healthcare professionals (doctors, diabetes advisors, diabetes assistants, dieticians, nutritionists, nursing staff, etc.). It is also recommended that bicultural and multilingual personnel be increasingly trained and promoted in health services. In anamnesis and therapy, it is important to consider bio-psycho-social influence factors and thus to keep religious attitudes as well as interfamilial and social hierarchies in mind ( Fig. 1).

\section{Language}

Communication during treatment should be in one language (treatment language). If necessary or possible, interpreting should be done by specialized interpreters or language and culture mediators.

Children are generally unsuitable as translators. If a professional interpreter is not available, adult relatives can be envolved to assist. It is advisable to communicate using clear, simple, short sentences and general terms. If necessary, another language (including colloquial language) can be used or medical personnel with appropriate language skills can be involved, taking into account the obligation of confidentiality.

The DocCards shown below are recommended as a practical orientation aid for the procedure in doctor-patient consultations with and without an interpreter (refer to DocCards under DDG working materials http://migration.deutsche-diabetes- gesellschaft.de/arbeitsmaterialien/doccards.html) (• Figs. 2, 3)

In their guidelines on patients' rights, the Federal Ministry of Health (Bundesministerium für Gesundheit) and the Federal Ministry of Justice (Bundesministerium für Justiz) point out that every patient has the right to adequate opportunities for communication and appropriate information and advice, as well as to careful and qualified treatment. However, they do not mention the financing of professional interpreting services ( shown in $>$ Fig. 4 is not valid for Austria.

\section{Nutrition}

Different cultures and regions can have very individual eating habits.

Food culture is shaped by geographical, historical, sociological, economic and psychological characteristics of a society and is shared by the corresponding members of a particular community. Culture is a fundamental determinant of "what we eat" [25].

Migrants often have different eating habits than natives. They sometimes prefer other foods, often eat more carbohydrates, have different meal concepts, a different understanding of portions, and different food preparation forms and food combinations. Their nutritional concepts are usually based on their own traditional cuisine, personal habits, and they also adopt the eating habits of the local population, often resulting in a new "mixed cuisine" [26]. It is not uncommon for special foods to be procured from the home countries. Migrants from some cultures have little use for the weight information in local recipes when cooking.

People have a highly variable postprandial glucose response to identical foods. Individualized culturally-sensitive counseling improves compliance [27].

In this context, fasting during Ramadan - religiously-influenced food selection and fasting regulations (see below), pregnancy and shift work play a special role.

In everyday practice, knowledge of the main carbohydrate sources and in what form and when the carbohydrates are eaten is indispensable. The following practice tool ( $\triangleright$ Table 1 ) for the nutrition of migrants is intended to provide initial information and assistance. A pragmatic regional breakdown with information on common cuisine forms the basis. The main sources of carbohydrates and other regional characteristics are presented in addition to the type (warm/cold) and number of meals. 
Bio-psycho-social influence factors

(Patient) Access

Communication (including decoding of culture-specific signals)

\section{Health/disease}

- Health condition

- Chronic illness

- Multimorbidity

- Rare illness

- Mental disorders

- Disabilities

\section{Ethnicity}

- Culture

- World view/norms

- Lifestyle

- Way of thinking/acting

- Understanding of

health/illness

- Genetics/genome
Social demographic, economic, psychosocial factors

\begin{tabular}{l|l}
$\begin{array}{l}\text { - } \text { Country of origin } \\
\text { - Country of socialization }\end{array}$ & $\begin{array}{l}\text { - Migration status } \\
\text { - Reason for migration } \\
\text { - Duration of time in the new } \\
\text { country } \\
\text { - Degree of education }\end{array}$ \\
$\begin{array}{l}\text { - Professional status } \\
\text { - Work situation }\end{array}$ \\
$\begin{array}{l}\text { - Marital status (single, single parent, etc.) } \\
\text { - Family situation (nuclear family, patchwork, extended family) } \\
\text { - Relationship situation (social hierarchies) } \\
\text { - Parent constellation (f/m/o) }\end{array}$ \\
\hline $\begin{array}{l}\text { - Gender, age, sexual orientation, phase of life and health } \\
\text { competencies }\end{array}$ \\
*includes language, tradition, conventions, customs, \\
rituals and religion.
\end{tabular}

Life circumstances

- Influence of family and

community

- Religiousness

- Environmental factors

- Form of society

\section{Lifestyle}

- Nutrition

- Physical activity

- Tobacco

- Alcohol

- Other addiction factors

- Personal responsibility/self

-management

- Fig. 1 Bio-psycho-social influence factors to be considered in the patient interview. @ Faize Berger, 2019.

Cuisines are quite diverse around the world and there is also a great deal of regional diversity. Nevertheless, it should be noted that many drinks have now made their way into many food cultures around the world, such as soft drinks, energy drinks, sweetened drinks and some beers.

\section{Training and Training Material}

Both culturally-sensitive individual training courses and target groupadapted group training courses enable effective communication of information about diabetes mellitus, its secondary and concomitant diseases, perception of hypo- and hyperglycemia and therapy.

Therapies tailored to the cultural needs of study participants in randomized controlled trials show a reduction in $\mathrm{HbA} 1 \mathrm{c}$ and body fat values [28].

Training materials with culturally-sensitive examples should be available at least in the respective native languages and ideally be bilingual.

The use of pictograms, illustrations, symbols, demonstration utensils, especially pen needles, test strips, applicators, blood glucose meters, etc. is recommended not only to reach the illiterate people with diabetes, but also to provide effective training.

It is important for the portion sizes to be accurate when creating images of food and the like. For illiterates, the use of blood glucose meters with a large display or speaking meters is recommended (also available in foreign languages). At present, there is hardly any training material available on diabetes technology in the context of migration. The instructions for use of the devices cannot replace the need for training materials.
A selection of foreign language information and training materials has been compiled on the homepage of the DDG's Working Group on Diabetes and Migrants. In addition, the DDG's Working Group on Diabetes and Migrants has actively brought together important institutions in order to provide professional, culturally-sensitive working materials for nutritional counseling in diabetes mellitus.

\section{Pregnancy - Gestational Diabetes Mellitus (GDM)}

GDM occurs with above-average frequency among women with a migration background [29], but due to the great heterogeneity, migrant women or women with a migration background in general do not represent a specific uniform risk group for GDM.

The extent of the influence depends on the prevalence of the individual risk factors, the ethnicity of the population concerned and the specific migration situation [30].

A retrospective analysis conducted in Austria clearly shows the diversity of the individual migrant populations in connection with GDM. Data from 3293 pregnant women in a university hospital between 2013 and 2015 were evaluated taking into account the country of birth. The GDM risk for Turkish immigrant women was approximately twice as high as the risk of pregnant women born in Austria. The risk was about 1.5 times higher for women from Romania, Hungary and Macedonia [29].

Risk factors favoring the development of GDM were observed significantly more frequently among migrant women from Turkey, the Near and Middle East and Africa than among women born in 

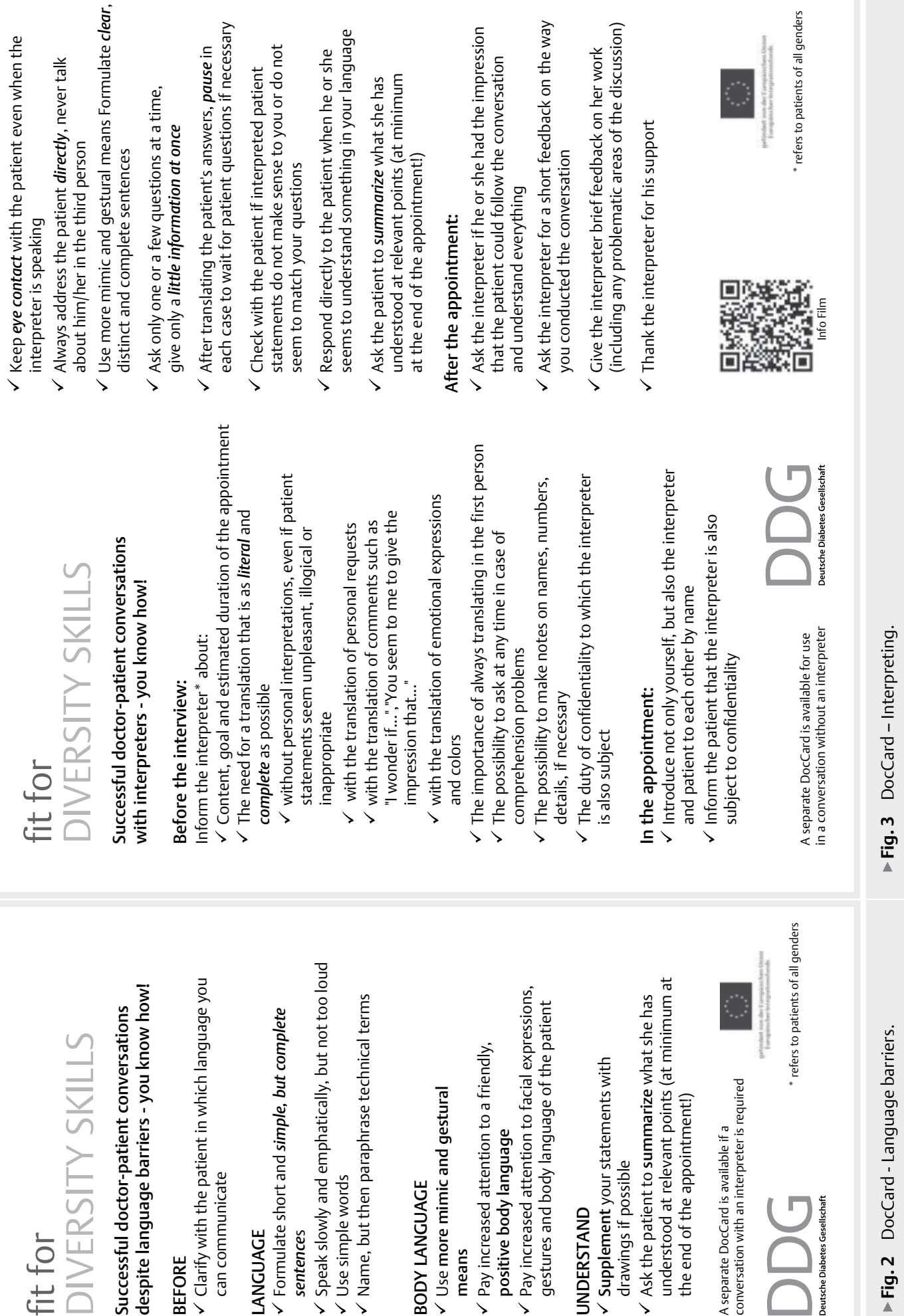
General conditions

- The obligations of disclosing information of the treating persons are regulated in $\S 630$ e BGB

- Guidelines of the BMG and BMJ are intended to inform service providers The right to adequate opportunities
for communication

Guidelines of the BMG and BMJ on patient rights in Germany

The patient bears the costs

Law for the improvement of patients' rights dated 2013-02-20
"The patient is entitled to appropriate information and consultation as well as careful and qualified treatment. Diagnostic and therapeutic measures must be coordinated with the patient. Every treatment requires the patient's cooperation. However, a success of treatment cannot be guaranteed despite the best therapy".

"The physician must inform the patient in good time before the treatment and in a personal consultation about the nature and extent of the measures and the associated health risks and obtain the patient's consent to them. Forms and information sheets are no substitute for the consultation."

There is no basic obligation of the practitioner to always communicate with patients who do not speak German via interpreter. If the practitioner is convinced that he/she cannot fulfill his/her duty of information, he/she must call in a person who is familiar with the language. According to the law for the improvement of the rights of patients, the costs for interpreting are to be borne by the patient.

Fig. 4 General conditions for the education of patients and service providers based on the BMG and BM] guidelines on patient rights in Germany 2005 [Source for the guidelines: Federal Ministry of Health and Federal Ministry of Justice (Bundesministerium für Gesundheit und Bundesministerium für Justiz) (2007): Patient rights in Germany, Guidelines for Doctors (Patientenrechte in Deutschland, Leitfaden für Ärztinnen/Ärzte). Berlin. https://www.bundesgesundheitsministerium.de/uploads/publications/BMG-G-G407-Patientenrechte-Deutschland.pdf (Dated: 2015-09-20)]] and the Law for the Improvement of Patients' Rights (Gesetz zur Verbesserung der Rechte von Patientinnen und Patienten) [Bundesgesetzblatt jahrgang 2013 Teil I Nr. 9, p. 277-282]. BMG: Federal Ministry of Health (Bundesministerium für Gesundheit), BM]: Federal Ministry of Justice (Bundesministerium für Justiz).

Austria or migrant women from other European countries. These include the genetically-higher risk of developing type 2 diabetes over the course of life, excess weight/obesity, higher parity and higher risk of GDM. Similarly, the probability of developing manifest type 2 diabetes mellitus later in life is also higher.

Women with a low socio-economic status and migration background often have difficulties in understanding the requirements for GDM self-management.

To improve adherence to treatment plans, they need education and support services that are culturally appropriate and that also aim at low levels of literacy [31].

\section{Obesity/excess weight}

In certain migrant populations - especially among women from the Middle East, Turkey, and North and South Africa - numerous studies have found a clear prevalence of excess weight and obesity. For pregnant women from Turkey and North Africa, a French birth cohort study of 18000 women also showed a significantly higher risk of excess weight/ obesity and GDM. Women from Eastern Europe and Asia, on the other hand, have a lower weight risk but still a higher risk of developing GDM than pregnant women without a migration background [32].

Pre-conception care of the migrant women already reduces the risk of complications.

\section{Nutrition}

During pregnancy, nutrition, coupled with cultural and traditional characteristics, is of increased importance. For example, it is commonly observed that pregnant women think that they should eat "for two". The idea of giving in to pregnancy cravings is also often consciously supported.

It is therefore absolutely essential to provide culturally-sensitive training, develop an individual nutrition plan and closely monitor its implementation and adaptation, especially with migrant women who come from risk regions. In the context of a planned or existing pregnancy it is essential to provide. The practice tool on nutrition ( $\vee$ Table 1 ) can be used for orientation and as a preliminary aid regarding the main carbohydrate sources in the respective native cuisine.

\section{Vitamin D deficiency}

Direct sunlight is very high in the country of origin for people from Africa, the Near and Middle East and the Indo-Asian region and they are usually undersupplied with regard to vitamin D status after migration to Europe. The results of studies on the effect of vitamin D deficiency on GDM are not clear [33]. In general, however, a vitamin $D$ deficiency is an avoidable health risk. 


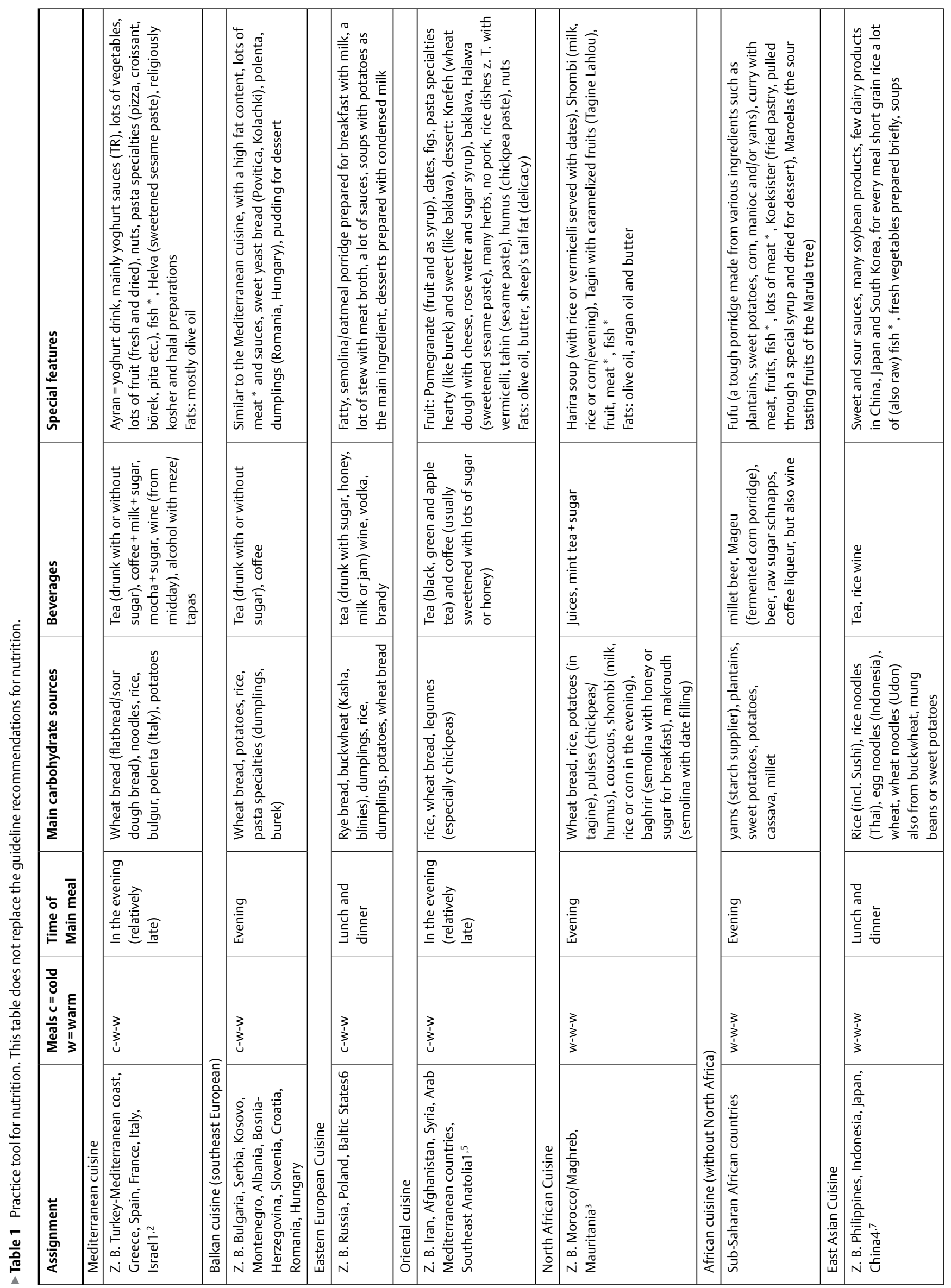




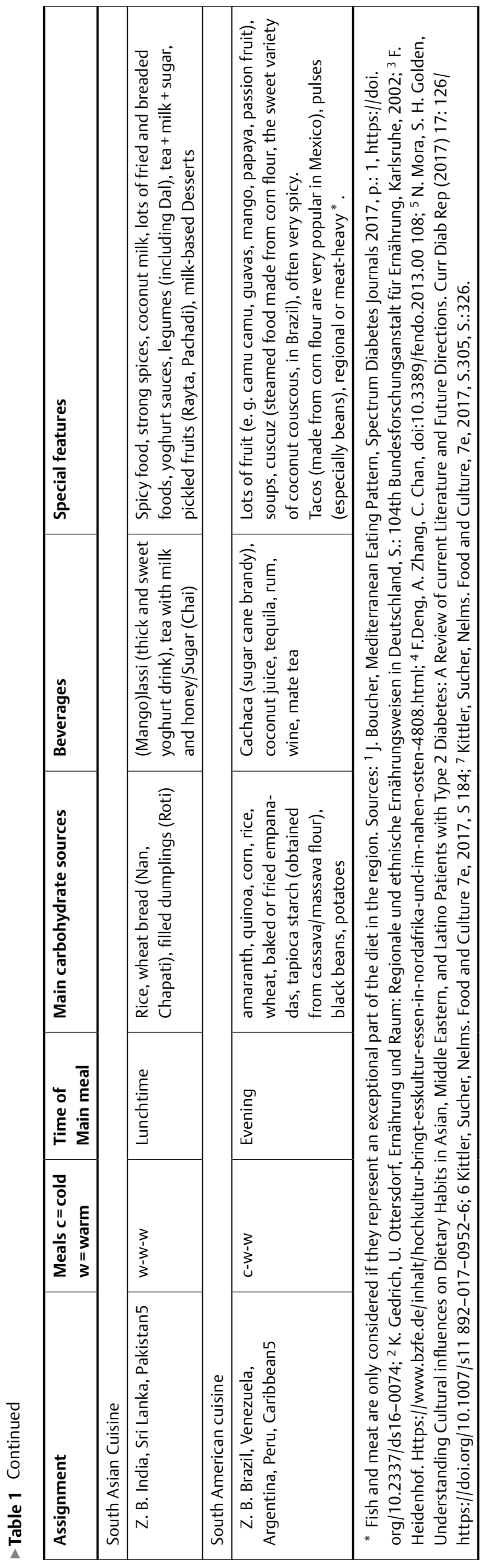

For this reason, the vitamin $\mathrm{D}$ status of pregnant migrant women from the above-mentioned regions in particular should be assessed and consideration should be given to minimizing the risk, if necessary, by substitution.

\section{Breastfeeding}

Breastfeeding the newborn for at least 3 months reduces the mother's risk of diabetes mellitus [34]. The World Health Organization (WHO) therefore recommends full breastfeeding for at least 6 months. "Initial analyses of the breastfeeding behavior surveyed in KiGGS show that children with a migration background are breastfed more frequently and also longer than those without a migration background. $88.1 \%$ of Russian-German children and $79.3 \%$ of children of Turkish origin were breastfed more frequently than children without a migration background (76.2\%).

The fact that only three-quarters of the children grouped under "other" migrants received breast milk is an impressive indication of the heterogeneity within the migrant population" [35].

Migrant women should be motivated to breastfeed for at least 6 months, especially if they are overweight/obese.

\section{Treatments with antibiotics}

Antibiotic therapy during pregnancy leads to disrupted development of the microbiome in the newborn's intestine [36] in the postnatal period. Especially among the women who have fled to Germany since 2015, it can be assumed that they may have been exposed to antibiotic therapy more frequently than native women with and without a migration background. On the one hand, the group described above is more likely to carry multi-resistant germs, which could be an indicator for antibiotic use, and on the other hand, culturally-determined convictions regarding antibiotic therapy are added. For example, therapy with antibiotics is almost a cultural norm in the Iraqi population, and patients regard the prescription of antibiotics as an adequate standard therapy.

\section{Therapeutic adherence and pregnancy testing for migrant women}

As with some other subgroups, migrant women are particularly at risk for GDM due to the often low level of education, communication deficits, low health skills, and high unemployment. Without professional help, they find it difficult to find their way around the healthcare system. They often know neither the care processes and the importance of preparing for pregnancy, nor the prenatal and postnatal examinations that are a regular part of medical care and preventative care in Germany. Doctors should inform their patients with a migration background about preventative care options at an early stage. Physicians in private practice, on the other hand, report that younger migrant women who are familiar with the care structures regularly attend pre- and postnatal check-ups and show at least comparable, if not significantly higher, compliance compared to native women of their age. On the other hand, there are women who come to a birthing center or hospital with labor pains and the medical team can hardly obtain information about the course of their pregnancy to date due to communication problems. The team may also encounter these pregnant women for the first time and find that they have received little or no medical advice or support during their pregnancy. In connection with diabetes, preg- 
nancy and migration, other factors such as health literacy, understanding of illness/health, influence and role of family, traditions, customs and rituals must also be taken into account. In the group of women who migrate because they are forced to flee and who have no proof of identity, other aspects such as traumatization, violence (including rape) and a higher number of abortions can be added in this context [37].

It would be desirable for the treating physicians to have a basic understanding of how pregnancy and maternity are understood in the respective cultures as well as basic psychosocial knowledge for dealing with trauma victims.

\section{Fasting in General}

Fasting is considered the voluntary complete or partial abstention from meals, beverages and luxury food over a certain period of time; this is in contrast to starving where a lack of food exists. There are different reasons for fasting: health, mental, religious or physical, among others.

Fasting type and duration can vary greatly depending on the reason for the fasting.

In the following, the fasting month of Ramadan is discussed in more detail.

\section{Ramadan - One Month of Fasting}

Approximately 1.6 billion people around the world live with Islamic religious beliefs. Ramadan is the month of fasting for Muslims and the ninth month of the Islamic lunar calendar [38]. Fasting during Ramadan lasts one month. During the fasting period, from sunrise (Sahur = meal at sunrise or beginning of fasting) to sunset (Iftar = meal after sunset or breaking of fasting), no liquid or food may be consumed. Due to the lunar calendar, the fasting period is shifted forward by about 10 to 11 days every year. People with chronic diseases (including pregnant women and nursing mothers) are not obliged to fast. Many faithful Muslims with chronic diseases insist nevertheless on fasting but this should only take place under medical supervision [39]. According to the EPIDIAR study, about $43 \%$ of patients with type 1 diabetes and about $79 \%$ with type 2 diabetes fasted for at least 15 days during Ramadan [40]. A retrospective, 13 -country study reported that $64 \%$ of patients fasted daily during Ramadan and $94 \%$ fasted for at least 15 days during that period [41]. Fasting is a special challenge for people with diabetes and their therapists. In general, an adjustment or modification of the existing therapy according to the current guideline recommendations of the DDG or ÖDG should be referred to before the start of the fasting period. If a person with diabetes wants to fast, the intake and dosages as well as the side effects (especially minimizing the risk of hypoglycemia) of the medication have to be adapted to the new eating habits. Since the main meal is at sunset, the day-night rhythm is reversed. In accordance with this rhythm, some medications, especially sulphonylureas and insulin therapy, need to be changed or their dosage adapted - the prevention of hypoglycemia is the main priority. Further complications during fasting are hyperglycemia, dehydration, increased risk of thrombosis and ketoacidosis [40].
In 2016, the IDF and DAR published a practice recommendation for patients with diabetes who want to fast during Ramadan [39]. Patients are assigned to different risk groups according to the assessment of their risk of developing one or more complications (as mentioned above) during fasting ( Fig. 5) [38].

\section{Therapeutic Dosage Suggestions during the Fasting Period of Ramadan}

The order of the substance groups does not correspond to the prioritization of the use according to the current guideline recommendation.

\section{Oral antidiabetic therapy [38] ( Table 2) \\ Metformin}

The dosage can be left as it is, it is taken with Sahur and iftar. If it is taken twice a day (e. g. $1000 \mathrm{mg}$ of metformin), the dosage should be left as it is. In case of a triple dose (e. g. $500 \mathrm{mg}$ of metformin) it is recommended to take $500 \mathrm{mg}$ of metformin with Sahur and 1000 mg with iftar.

Acarbose

It is recommended to take it with meals without changing the dosage.

\section{Sulfonylureas (SH)}

The basic recommendation is to change to another substance class with a lower risk of hypoglycemia in accordance with the currently-valid guidelines of the DDG or ÖDG.

If the $\mathrm{SH}$ therapy is nevertheless to be continued, a change to the newer generations of sulfonylureas (e. g. gliclazide, glimepiride) is recommended. In case of one single dose, a dose reduction of $25 \%$ is recommended, as well as timing the dose to breaking the fast (Iftar). If two doses are taken, it is recommended to reduce the morning dose as well (or skip it if no meal is taken with Sahur) and take the second dose for breaking the fast without changing the dose.

\section{Glitazones}

The dose is recommended without reduction with iftar or Sahur.

\section{Dipeptidyl peptidase 4 inhibitor (DPP-4 inhibitor)}

Recent data show that DPP-4 inhibitors (especially vildagliptin, sitagliptin) are a safe therapeutic alternative during fasting. The $\mathrm{HbA1C}$ value did not differ significantly from SH [42]. The use of DPP-4 inhibitors resulted in a lower risk of mild, symptomatic and severe hypoglycemia compared to $\mathrm{SH}[42,43]$. The dose of a DPP-4 inhibitor is not changed and can be taken at iftar [38].

\section{Glucagon-like peptide-1 receptor agonist (GLP1-RA)}

In the Treat-for-Ramadan study, liraglutide showed a lower risk of hypoglycemia than $\mathrm{SH}$, as well as improvements in $\mathrm{HbA} 1 \mathrm{c}$ and weight loss [39]. In addition, the LIRA-Ramadan study demonstrated the efficacy and safety of liraglutide over a 52-week observation period including fasting [39]. Liraglutide resulted in an improvement in fasting glucose levels, sustained weight loss and a reduction in HbA1c [43]. 


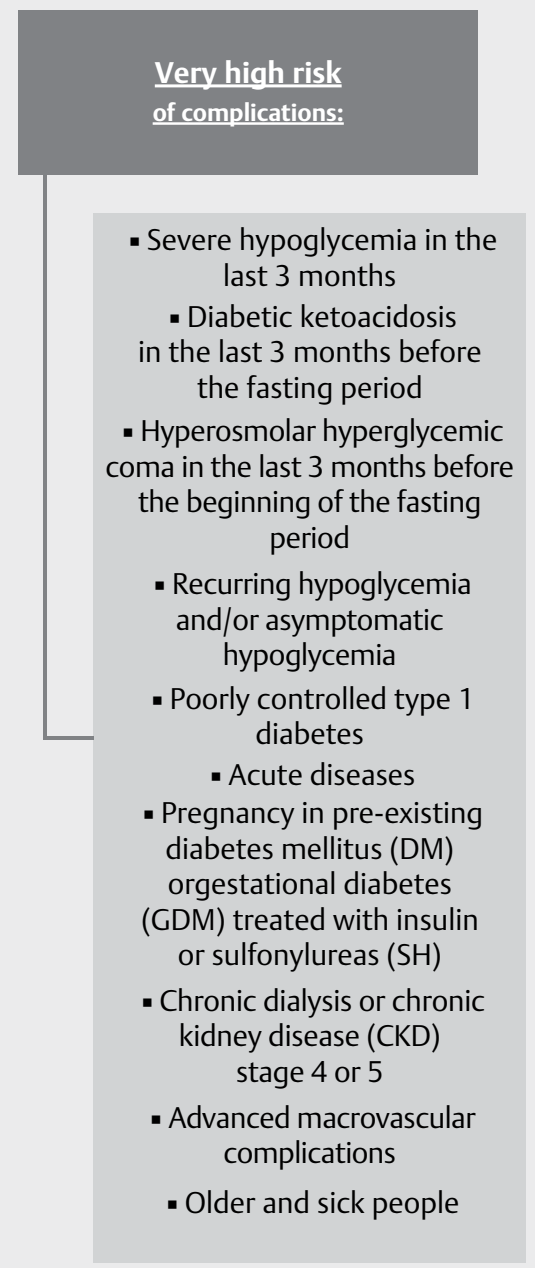

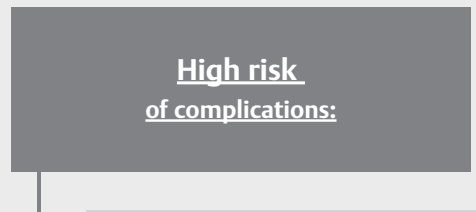

- Persistent poorly-controlled type 2 diabetes

- Well-controlled type 1 diabetes

- Well-controlled type 2

diabetes under ongoing

mixed insulin or basic bolus therapy

- Pregnant mothers with type 2 diabetes or GDM only under diet or metformin therapy

- Chronic kidney disease - CKD stage 3

- Stable macrovascular complications

- Persons with comorbid conditions, which represent additional risk factors

- Persons with diabetes, who do intensive physical work

- Treatment with drugs that can impair cognitive function
Moderate or

low risk

of complications:

- Persons with well-controlled type 2 diabetes treated with one or more of the following therapies:

- Lifestyle modification

- Metformin

- Acarbose

- Thiazolidindione

- Sulfonylureas (SH)

- Incretin-based therapies

(DPP-4 inhibitor or GLP-1-RA)

- SGLT-2 inhibitor

- Basal insulin

- Fig. 5 Risk assessment regarding the occurrence of one and/or more complications during the fasting period.

- Table 2 Therapy dosage suggestions during Ramadan for oral antidiabetic therapy.

\begin{tabular}{|c|c|c|c|}
\hline \multirow[t]{2}{*}{ Medicine [38] } & \multicolumn{2}{|l|}{ Adjustments } & \multirow[t]{2}{*}{ Particularities } \\
\hline & Dose modification & Time of administration & \\
\hline Metformin & Yes & With Iftar 1 and Sahur 2 & $\begin{array}{l}\text { Skip lunchtime dose, } \\
\text { For } 2 \times 1000 \mathrm{mg} \text { : maintain dose with iftar and Sahur, } \\
\text { For } 3 \times 500 \mathrm{mg} \text { : with iftar } 1000 \mathrm{mg} \text { and Sahur } 500 \mathrm{mg}\end{array}$ \\
\hline Acarbose & None & With Iftar and Sahur & \\
\hline Sulfonylurea & yes & $\begin{array}{l}\text { Morning dose with Iftar, } \\
\text { evening dose with Sahur }\end{array}$ & $\begin{array}{l}\text { Preferably change SH therapy to another substance group with low risk of } \\
\text { hypoglycemia. } \\
\text { If SH-therapy is prescribed further, then preferably glimepiride or gliclazide, } \\
\text { avoid glibenclamide. } \\
\text { For single administration: take with iftar, } 25 \% \text { dose reduction with good } \\
\text { control, if necessary. } \\
\text { If administered twice: reduce morning dose with Sahur by } 25 \% \text { if necessary. }\end{array}$ \\
\hline Glitazone & None & With Iftar or Sahur & \\
\hline DPP-4 inhibitors & None & With Iftar & \\
\hline GLP1 agonists & None & With Iftar or Sahur & \\
\hline SGLT2-inhibitors & None & With Iftar & $\begin{array}{l}\text { Ensure that enough liquid is drunk after breaking the fast (Iftar) until Sahur! } \\
\text { Caution with insulin deficiency: danger of euglycemic diabetic ketoacidosis [38]. }\end{array}$ \\
\hline
\end{tabular}


- Table 3 Therapy dosage suggestions during the fasting period of Ramadan for the insulin therapy.

\begin{tabular}{|c|c|c|c|c|c|}
\hline \multirow{2}{*}{$\begin{array}{l}\text { Therapy (insulin) } \\
\text { [38] }\end{array}$} & \multirow[t]{2}{*}{ Adjustment } & \multicolumn{3}{|l|}{ Dosage } & \multirow[t]{2}{*}{ Particularities } \\
\hline & & One dose & Two doses & Three doses & \\
\hline \multirow[t]{2}{*}{$\begin{array}{l}\text { BOT-basal supported } \\
\text { oral therapy }\end{array}$} & Dose change & $\begin{array}{l}\text { Dose reduction } \\
15-30 \%\end{array}$ & $\begin{array}{l}\text { Reduce the dose with Iftar } 1 \\
15-30 \% \text { and reduce the dose with } \\
\text { Sahur } 2 \text { by } 50 \% \text {. }\end{array}$ & - & \\
\hline & Administration & With Iftar & $\begin{array}{l}\text { Move the morning dose to Iftar and } \\
\text { move the evening dose to Sahur }\end{array}$ & - & \\
\hline \multirow{2}{*}{$\begin{array}{l}\text { Rapid-acting insulin } \\
\text { - functional insulin } \\
\text { therapy }\end{array}$} & Dose change & None & $\begin{array}{l}\text { iftar dose unchanged, reduce } \\
\text { Sahur dose by } 25-50 \%\end{array}$ & $\begin{array}{l}\text { Reduce Sahur dose by } \\
25-50 \%\end{array}$ & \multirow[t]{4}{*}{$\begin{array}{l}\text { Analog insulin } \\
\text { recommended }\end{array}$} \\
\hline & Administration & With Iftar & Iftar and Sahur & Skip midday dose & \\
\hline \multirow[t]{2}{*}{ Mixed insulin } & Dose adjustment & None & Reduce Sahur dose by $25-50 \%$ & $\begin{array}{l}\text { Skip midday and } \\
\text { reduce Sahur dose by } \\
25-50 \%\end{array}$ & \\
\hline & Administration & Move to Iftar & $\begin{array}{l}\text { Move morning dose to Iftar, } \\
\text { move evening dose to Sahur }\end{array}$ & $\begin{array}{l}\text { Skip midday dose, } \\
\text { otherwise the same as } \\
\text { two doses }\end{array}$ & \\
\hline Insulin pump & Dose change & \multicolumn{3}{|c|}{$\begin{array}{l}\text { Reduce the basal rate by } 20-40 \% 3-4 \text { h before iftar, shortly after iftar: increase } \\
\text { by } 0-30 \%\end{array}$} & $\begin{array}{l}\text { Insulin bolus depends on } \\
\text { carbohydrate amount } \\
\text { and insulin sensitivity }\end{array}$ \\
\hline
\end{tabular}

Sodium-dependent glucose transporter-2-Inhibitor (SGLT2-Inhibitor)

No dose reduction is recommended for this, the dose can be taken with iftar. It is important to drink enough liquids after breaking the fast (iftar) up to Sahur. Taking SGLT2-inhibitors is possible for welladjusted diabetes patients with stable metabolism, good kidney function and who do not have an increased risk of dehydration [44].

In principle, the risk of hypoglycemia is low and the weight reduction caused by renal glucosuria is beneficial. However, given the risk of euglycemic diabetic ketoacidosis, caution is advised in cases of insulin deficiency [45]. Ketone measurements are required for all patients who decide to fast and are on SGLT2-inhibitor therapy [46].

\section{Combination preparations of different substance classes}

The hypoglycemic effects and corresponding dosage recommendation or adaptations of the respective substance groups must be taken into account, as already mentioned above.

\section{Insulin therapy during fasting ( $\triangleright$ Table 3 )}

\section{BOT - basal-supported oral therapy}

It is recommended to reduce the single basal insulin daily dose by 15 to $30 \%$ and to slowly adjust the dose during the fasting period according to the glucose metabolism.

Double administration of basal insulin should be distributed as follows: the usual morning dosage is administered with iftar (sunset) and the evening dosage at a $50 \%$ reduction should be administered with Sahur (sunrise) $[38,42]$.

\section{Rapid or short-acting prandial/bolus insulin}

The usual dosage is to be administered according to the carbohydrate source to iftar. The administration of insulin at noon should be omitted. For Sahur, an initial dose reduction of 25 to $50 \%$ is recommended and the dosage should be adjusted as needed. Func- tional insulin therapy (FIT) can be derived from the above recommended dose adjustment of basal and prandial insulins.

\section{Mixed insulin}

For single administration: administer usual dosage with iftar. For double administration: usual morning dosage with iftar, reduce usual evening dosage by $25-50 \%$ and administer with Sahur. In case of three administrations: skip midday dose, otherwise apply as recommended for two administrations and gradually adjust the dose. A dose titration (if necessary, according to a prescribed scheme) should be performed every three days according to the glucose value. Close monitoring or consultation with the doctor in charge or the diabetes team is recommended.

\section{Insulin pump therapy}

The basal rate should be reduced by $20-40 \%$ in the last 3 to $4 \mathrm{~h}$ of fasting. Shortly after iftar an increase of the basal dose by $0-30 \%$ is recommended. The bolus dose should be administered depending on the carbohydrate amount consumed and the respective insulin sensitivity.

\section{Breaking the Fast}

Each patient should be informed about the possibility of breaking the fast. In particular, symptoms of hypoglycemia or hyperglycemia should be taken seriously and reacted to accordingly. In case of an unforeseeable event or an acute complication (e.g. acute illness, massive blood glucose derailment) the fasting should be interrupted immediately. Fasting can be ended by ingesting a liquid containing carbohydrates or with solid food.

In the case of hypoglycemia with typical symptoms, prompt glucose measurement is recommended after an appropriate intake of fast-acting carbohydrates. 
In case of unclear symptoms of blood glucose derailment (unclear differentiation between hypoglycemia and hyperglycemia) and refusal to break the fast, immediate glucose measurement is recommended and should be reacted to according to the values listed below.

All patients should interrupt fasting when [38]:

1. The glucose value is $<70 \mathrm{mg} / \mathrm{dl}(3.9 \mathrm{mmol} / \mathrm{l})$

2. The glucose value is $>300 \mathrm{mg} / \mathrm{dl}(16.7 \mathrm{mmol} / \mathrm{l})$ and/or

3. Symptoms of hypoglycemia or an acute illness have occurred.

\section{Acknowledgement}

The authors of the practice recommendations thank the practice team of Sebahat Sat and the members of the Transcultural Consulting Team for their commitment in the development of the practical tool for nutrition; Susa Schmidt-Kubeneck for editing and interface function to the DDG's office; the Nutrition Committee of the DDG, the Commission on Epidemiology and Health Services Research of the DDG and the Diabetes and Pregnancy Working Group of the DDG for contributing their expertise.

\section{Conflict of Interest}

Kadriye Aydınkoç-Tuzcu has received research grants and/or fees from the following companies, which are also supporting members of the ÖDG Abbott, AstraZeneca, Bayer Health Care, Bristol-Meyer Squibb, Germania Pharmazeutika, GlaxoSmithKline Pharma, Eli Lilly, Merck Serono, Merck Sharp \& Dohme, Novartis, Novo Nordisk, Pfizer, Roche, Sanofi-Aventis, Takeda. In addition, Kadriye Aydınkoç-Tuzcu states that she personally has no conflict of interest. Alain Barakat indicates the following potential conflicts of interest: Lecturing activities for Sanofi, Novo-Nordisk, Lilly, Astra-Zeneca; research activities for Mitsubishi-Tanabe, Novo-Nordisk, Novartis, Gan-Lee, Daiichi Sankyo, Innocoll. Lecturing and research activities had no effect on the preparation of the practice recommendations. Faize Berger states that there is no conflict of interest. Peter Fasching has received research grants and/or fees from the following companies, which are also supporting members of the ÖDG Abbott, AstraZeneca, Bayer Health Care, Boehringer Ingelheim, Bristol-Myers Squibb, Daiichi-Sankyo, Germania Pharmazeutika, GlaxoSmithKline Pharma, Eli Lilly, Merck Serono, Merck Sharp \& Dohme, Novartis, Novo Nordisk, Pfizer, Roche, Sanofi-Aventis, Servier, Takeda. Peter Fasching discloses that during this period he received fees for lectures and consulting services from the companies mentioned above, or that he received further training support within the scope of the (service) legal framework (invitation to congresses), or that he conducted or is conducting clinical studies as a PI with individual companies. In addition, Peter Fasching states that he personally has no conflict of interest. Sebahat Şat discloses holding lectures for Boehringer Ingelheim, Santis, Sanofi. In addition, Sebahat Şat states that she has no conflict of interest. Karin Schindler states that there is no conflict of interest.

\section{References}

[1] www.destatis.de/DE/Themen/Gesellschaft-Umwelt/Bevoelkerung/ Migration Integration/Methods/MigrationBackground. html?nn $=208952$

[2] Robert Koch Institute, ed Health in Germany. Health Reporting of the Federal Government. Jointly supported by RKI and Destatis. Berlin: RKI; 2015. doi:10.17886/rkipubl-2015-003-3
[3] Berger F. Type 2 diabetes and migrants: People from different language and cultural areas. Diabetology 2018; 13: 241-255. doi:10.1055/s-0043-124751

[4] Federal Statistical Office, Wiesbaden. Press Release No. 279 of July 28 , 2020. on the Internet (as of July 28,2020 ) http://www.destatis.de/DE/ Press/Press Releases/2020/07/PD20_279_12511.html

[5] Federal Statistical Office, Wiesbaden. Press Release No. 261 of August 2017. on the internet: www.destatis.de/DE/Presse/Pressemitteilungen/2017/08/PD17_261_12511.html, as of 03/05/2019

[6] Federal Office for Migration and Refugees. The Federal Office in figures 2017, asylum, migration and integration. Nuremberg: BAMF. 2018. on the Internet: www.bamf.de/SharedDocs/Anlagen/DE/Publikationen/ Broschueren/bundesamt-in-zahlen-2017.html status: 03.05.2019

[7] Jacobs E, Rathmann W. Epidemiology of diabetes. Diabetology and metabolism 2017; 12: 437-446. doi:10.1055/s-0043-120034

[8] Tenkorang EY. Early onset of type 2 diabetes among visible minority and immigrant populations in Canada. Ethnicity \& Health 2017; 22: 266-284. doi.org/10.1080/13557858.2016.1244623

[9] Aydinkoc K et al. Diabetes prevalence and diabetes-specific knowledge among Turkish migrants. ÖDG Autumn Conference 2011. p. 28 on the Internet www.oedg.at/pdf/1111_OEDG_JT_Programm.pdf as of 11.06.2018. Please contact the corresponding author of the ÖDG

[10] Meeks KA, Freitas-Da-Silva D, Adeyemo A et al. Disparities in type 2 diabetes prevalence among ethnic minority groups resident in Europe: a systematic review and meta-analysis. Internal and Emergency Medicine 2016; 11: 327-340. doi.org/10.1007/s11739-015-1302-9

[11] Ujcic-Voortman JK, Schram MT, Jacobs-van der Bruggen MA et al. Diabetes prevalence and risk factors among ethnic minorities. European Journal of Public Health 2009; 19: 511-515. doi. org/10.1093/eurpub/ckp096

[12] Stirbu I, Kunst AE, Bos V et al. Differences in avoidable mortality between migrants and the native Dutch in The Netherlands. BMC Public Health 2006; 6: 78. doi.org/10.1186/1471-2458-6-78

[13] Li X, Sundquist J, Zöller B et al. Risk of hospitalization for type 2 diabetes in firstand second-generation immigrants in Sweden: a nationwide follow-up study. Journal of Diabetes and its Complications 2013; 27: 49-53. doi:10.1016/j.jdiacomp.2012.06.015

[14] Vandenheede H, Deboosere P, Stirbu I et al. Migrant mortality from diabetes mellitus across Europe: the importance of socio-economic change. European Journal of Epidemiology 2012; 27: 109-117. doi:10.1007/s10654-011-9638-6

[15] Sivaprasad S, Gupta B, Gulliford MC et al. Ethnic variations in the prevalence of diabetic retinopathy in people with diabetes attending screening in the United Kingdom (DRIVE UK). PLoS One 2012; 7: e32182. doi.org/ 10.1371/journal.pone.0032182

[16] Reeske A, Zeeb H, Razum O et al. Differences in the Incidence of Gestational Diabetes between Women of Turkish and German Origin: An Analysis of Health Insurance Data From a Statutory Health Insurance in Berlin, Germany (AOK), 2005-2007. Geburtshilfe und Frauenheilkunde 2012; 72: 305-310. doi:10.1055/s-0031-1280428

[17] Migration and Integration, Statistical Yearbook 2020, Statistics Austria and Federal Chancellery (Statistik Austria und Bundeskanzleramt) -Integration Section, Statistisches_Jahrbuch_migration_integration_2020.pdf

[18] Schmutterer I, Delcour J, Griebler R. Ed. Austrian Diabetes Report 2017 (Österreichischer Diabetesbericht 2017). Vienna: Federal Ministry of Health and Women (Wien: Bundesministerium für Gesundheit und Frauen); 2017

[19] IDF Diabetes Atlas 8th Edition 2017 - www.diabetesatlas.org/ across-the-globe.html; Dated July 15, 2018

[20] K. Aydinkoc et al. Diabetes prevalence and diabetes-specific knowledge among Turkish migrants, ÖDG autumn conference. 2011 (Diabetesprävalenz und Diabetes-spezifisches Wissen bei türkischen MigrantInnen, ÖDG-Herbsttagung). p. 28. www.oedg.org/pdf/1111_ OEDG_JT_Programm.pdf. Accessed: June 11, 2018 
[21] statistics A. Austrian Health Survey (Österreichische Gesundheitsbefragung) 2006/2007. Family and youth. Socio-demographic and socioeconomic determinants of health; Federal Ministry of Health (Bundesministerium für Gesundheit) 2007

[22] Kirkcaldy B, Wittig U, Furnham A et al Migration and Health. Psychosocial Determinants. Bundesgesundheitsblatt Gesundheitsforschung Gesundheitsschutz 2006; 49: 873-883

[23] White JS, Hamad R, Li X et al. Long-term effects of neighbourhood deprivation on diabetes risk: quasi-experimental evidence from a refugee dispersal policy in Schweden. Lancet Diabetes \& Endocrinology 2016; 4: 517-524. doi.org/10.1016/S2213-8587(16)30009-2

[24] Statistics A. Austrian Health Survey 2006/2007. Federal Ministry of Health, Family and Youth. Sociodemographic and socioeconomic determinants of health. 2007

[25] Diker O, Deniz T, Çetinkaya A. History of Turkish Cuisine Culture and the Influence of the Balkans. IOSR Journal of Humanities And Social Science 2016; 21: 01-06. doi:10.9790/0837-2110060106

[26] Schmid B. Nutrition and Migration, Empirical Studies on the Nutritional Behavior of Italian, Greek and Turkish Migrant Women in Germany.Munich: Herbert UTZ Verlag; 2003 Chapter 1, S1

[27] Magni P, Bier DM, Pecorelli S et al. Perspective: Improving Nutritional Guidelines for Sustainable Health. Advances in Nutrition 2017; 8: 532-545. doi: 10.3945/an.116.014738

[28] Mora N, Golden SH. Understanding Cultural Influences on Dietary Habits in Asian, Middle Eastern, and Latino Patients with Type 2 Diabetes: A Review of Current Literature and Future Directions. Current Diabetes Reports 2017; 17: 126. doi:10.1007/s11892-017-0952-6

[29] Weiss C, Oppelt P, Mayer RB. The participation rate of migrant women in gestational diabetes screening in Austria: a retrospective analysis of 3293 births. Arch Gynecol Obstet 2019; 299: 345-351

[30] Pu J, Zhao B, Wang EJ et al. Racial/Ethnic Differences in Gestational Diabetes Prevalence and Contribution of Common Risk Factors. Paediatr Perinat Epidemiol 2015; 29: 436-443. doi:10.1111/ ppe.12209

[31] Carolan M, Gill GK, Steele C. Women's experiences of factors that facilitate or inhibit gestational diabetes self-management. BMC pregnancy and childbirth 2012; 12: 99. doi:10.1186/1471-2393-12-99

[32] El-Khoury Lesueur F, Sutter-Dallay AL, Panico L et al. The perinatal health of immigrant women in France: a nationally representative study. International Journal of Public Health 2018; 63: 1027-1036. doi 10.1007/s00038-018-1146-y

[33] Eggemoen AR, Wiegels Waage C, Sletner L et al. Vitamin D, Gestational Diabetes and Measures of Glucose Metabolism in a PopulationBased Multiethnic Cohort. J Diabetes Res 2018; 2018: 8939235. doi: 10.1155/2018/8939235 PMID: 29850611; PMCID: PMC5933024

[34] Ziegler AG, Wallner M, Kaiser I et al. Long-Term Protective Effect of Lactation on the Development of Type 2 Diabetes in Women with Recent Gestational Diabetes Mellitus. Diabetes 2012; 61: 3167-3171
[35] Lange C, Schenk L, Bergmann R. Distribution, duration and temporal trend of breastfeeding in Germany. Results of the Child and Adolescent Health Survey (KiGGS). Federal health sheet 2007; 50: 624-633

[36] Shane AL. Missing Microbes: How the Overuse of Antibiotics Is Fueling Our Modern Plagues. Emerg Infect Dis 2014; 20: 1961. doi:10.3201/ eid2011.141052

[37] Berger F. Diabetes and pregnancy among migrant women.In: Stupin JH, Schäfer-Graf U, Hummel M, ed Diabetes in pregnancy. Berlin: de Gruyter; 2020: 301-310

[38] Hassanein M, Al-Arouij M, Hamdy O et al. Diabetes and Ramadan: Practical guidelines. Diabetes Research and Clinical Practice 2017; 126: 303-316. doi: 10.1016/j.diabres.2017.03.003

[39] International Diabetes Federation (IDF) and the Diabetes and Ramadan DAR International Alliance Practical Guidelines.Brussels, Belgium: International Diabetes Federation; 2016: 108-114 www.idf.org/ guidelines/diabetes-in-ramadan Stand: 25.07.2019

[40] Salti I, Bénard E, Detournay B et al. A population-based study of diabetes and its characteristics during the fasting month of Ramadan in 13 countries: results of the epidemiology of diabetes and Ramadan 1422/2001 (EPIDIAR) study. Diabetes Care 2004; 27: 2306-2311. doi:10.2337/diacare.27.10.2306

[41] Babineaux SM, Toaima D, Boye KS et al. Multi-country retrospective observational study of management and outcomes of patients with type 2 diabetes during Ramadan in 2010(CREED). Diabetic Medicine 2015; 32: 819-828. doi: 10,1111/dme.12685

[42] Loh HH, Yee A, Loh HS et al. Comparative studies of dipeptidyl peptidase 4 inhibitor vs sulphonylurea among Muslim Type 2 diabetes patients who fast in the month of Ramadan: A systematic review and meta-analysis. Primary Care Diabetes 2016; 10: 210-219. doi:10.1016/j.pcd.2015.09.001

[43] Azis KMA. Fasting during Ramadan: efficacy, safety, and patient acceptability of vildagliptin in diabetic patients, Kamran MAAziz. Diabetes Metabolic Syndrom and Obesity 2015; 16: 207-211. doi:10.2147/DMSO.S54683

[44] Salem BA, Farooqi MH, Suliman SG et al. Use of Sodium-Glucose CoTransporter 2 Inhibitors during de Fasting of Ramadan: Is there cause for concern? Ibnosina. Journal of Medicine and Biomedical Sciences 2015; 8: 81-88. doi:10.4103/1947-489X.210221

[45] Ali S, Davies MJ, Brady EM et al. Guidelines for managing diabetes in Ramadan. Diabetic Medicine 2016; 33: 1315-1329. doi: 10.1111/ dme. 13080

[46] Ibrahim M, Davies M], Ahmad E et al. Recommendations for management of diabetes during Ramadan: update 2020, applying the principles of the ADA/EASD consensus. doi:10.1136/bmjdrc-2020-001248 